\title{
Фазовые дислокации в полых микроструктурированных световодах
}

\author{
А.Д. Прямиков \\ Российский химико-технологический университет им. Д.И. Менделеева \\ Институт общей физики им. А.М. Прохорова Российской академии наук
}

\section{E-mail: pryamikov@mail.ru}

DOI: 10.31868/RFL2020.30-31

История микроструктурированных световодов уже насчитывает свыше двух десятков лет. Особую роль среди них играют полые микроструктурированные световоды (ПМС) различных типов. Исторически первыми среди них по праву считаются полые фотонно - кристаллические световоды с сердцевиной круглой формы [1]. Отражение света в них основано на существовании фотонных запрещенных зон, при этом в лучших образцах таких ПМС из кварцевого стекла достигались потери на уровне 5 Дб/км. Основной проблемой, связанной с изготовлением этих ПМС является сложная структура оболочки, представляющая собой двумерный фотонный кристалл и сравнительно узкие зоны пропускания излучения в полой сердцевине. Другим типом ПМС, относящимся к классу фотонно - кристаллических световодов, был ПМС с оболочкой в виде фотонного - кристалла типа Kagome [1]. Потери в таких ПМС значительно выше, чем в предыдущем случае, но при этом зоны пропускания значительно шире за счет уменьшения толщины элементов оболочки. Механизм локализации света в сердцевине такого ПМС основан, по мнению его создателей, на слабой связи между модой полой сердцевины и модами сложной оболочки. В 2011 году был предложен другой тип ПМС из кварцевого стекла, не имеющий фотонно кристаллической структуры оболочки. Оболочка такого ПМС состояла только из 8 капилляров с определенно подобранной толщиной стенки. Эксперименты показали, что такой ПМС способен пропускать излучение вплоть до среднего ИК спектрального диапазона, где потери в кварцевом стекле делают его непрозрачным.
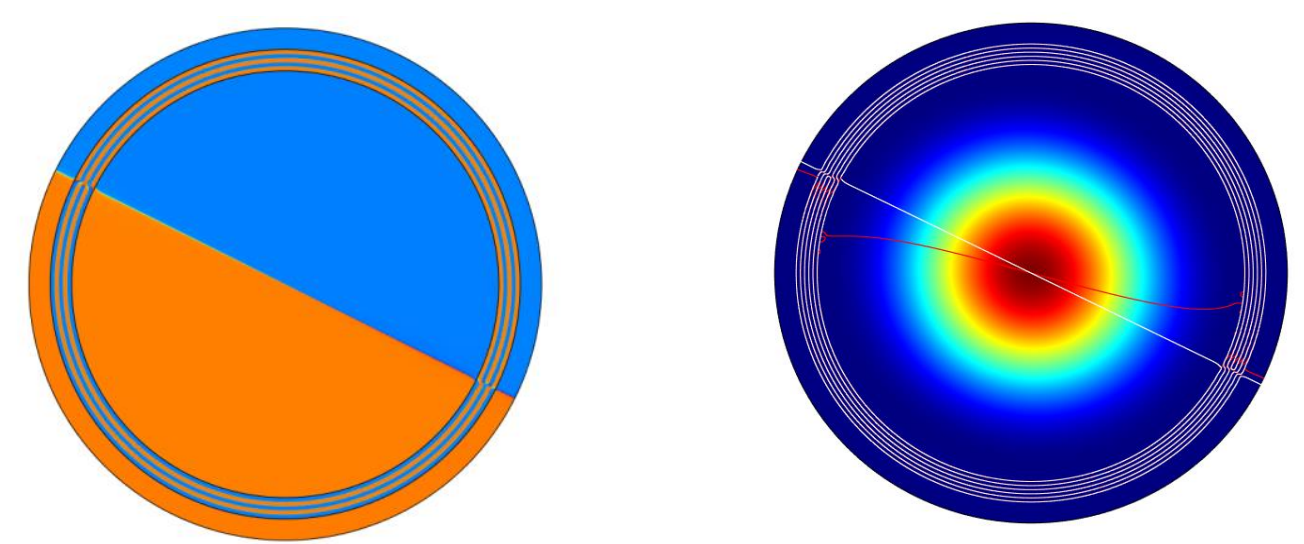

Рис. 1. Распределение фазы компоненты электрического поля $E_{\mathrm{z}}$ основной моды $\mathrm{HE}_{11}$ капилляра, на длине волны $\lambda=10.3$ мкм, скачок фазы при смене цвета на $\pi$ (левый рисунок), при этом в стенке капилляра в двух местах явно видны фазовые дислокации; линии $\operatorname{Im}\left(E_{\mathrm{z}}(\mathrm{x}, \mathrm{y})\right)=0$ (белая) и $\operatorname{Re}\left(E_{\mathrm{z}}(\mathrm{x}, \mathrm{y})\right)=0$ (красная) для моды $\mathrm{HE}_{11}$ (правый рисунок). Толщина стенки капилляра 25 мкм, показатель преломления 1.45 . 

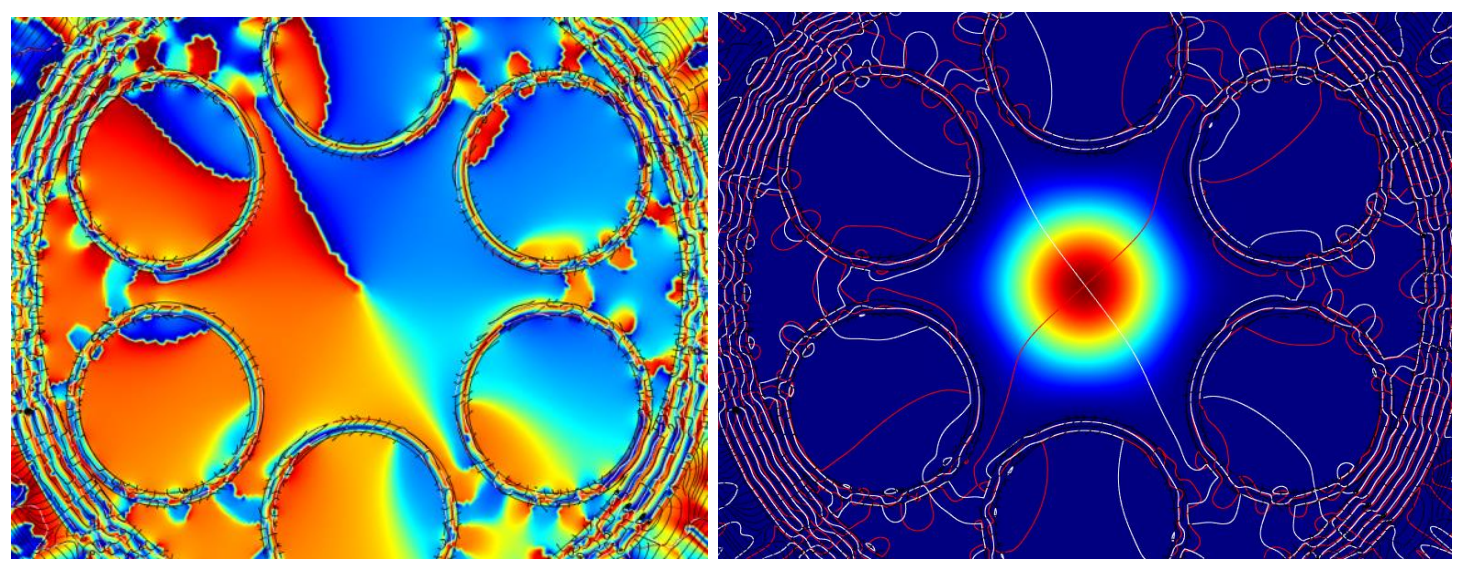

Рис. 2. Распределение фазы компоненты электрического поля $E_{\mathrm{z}}$ основной моды НЕ 11 ПМС из кварцевого стекла с оболочкой из 6 капилляров на длине волны $\lambda=4.3$ мкм с реальными материальными потерями (3173 Дб/м), полные потери составили 1.5 Дб/м, фаза непрерывно изменяется от - $\pi$ (синий цвет) до $\pi$ (красный цвет) (левый рисунок); линии $\operatorname{Im}\left(E_{\mathrm{z}}(\mathrm{x}, \mathrm{y})\right)=0$ (белая) и $\operatorname{Re}\left(E_{\mathrm{z}}(\mathrm{x}, \mathrm{y})\right)=0$ (красная) для моды $\mathrm{HE}_{11}$ (правый рисунок).

Стоит отметить, что все моды сердцевины рассмотренных выше ПМС являются вытекающими, поэтому аксиальные компоненты полей основной моды полой сердцевины имеют как действительную, так и мнимую часть. Если скалярное поле представить в виде $E(x, y)=\operatorname{Re}(E(x, y))+i \operatorname{Im}(E(x, y))$, то фазовые дислокации могут возникать в скалярном поле при наложении или пересечении кривых $\operatorname{Re}(E(x, y))=0$ и $\operatorname{Im}(E(x, y))=0$ в той или иной области плоскости поперечного сечения волновода [2]. В нашем случае роль такого скалярного поля играют аксиальные компоненты полей основной моды полой сердцевины $E_{z}$ и $H_{z}$. Приведем пример расчета распределения фазы и линий $\operatorname{Re}\left(E_{z}\right)=\operatorname{Im}\left(E_{z}\right)=0$ для обычного капилляра и ПМС с оболочкой из 6 капилляров в среднем ИК диапазоне (Рис. 1 и 2). Из рисунков видно, что фазовые дислокации для компоненты $E_{z}$ моды $\mathrm{HE}_{11}$ и, соответственно, компонент поперечной составляющей вектора Пойнтинга этой моды должны оказывать влияние на степень локализации излучения в полой сердцевине и полные потери в ПМС. В [3] мы демонстрируем этот факт не только на примере ПМС, но и на примере твердотельных микроструктурированных световодов. В настоящее время считается, что ПМС с оболочкой, состоящей из капилляров или hollow core negative curvature fibers, могут быть использованы для передачи высокомощного лазерного излучения, а также в будущих линиях связи, при условии получения в них потерь на уровне современных телекоммуникационных твердотельных световодов. Последние эксперименты, проведенные в ORC (University of Southampton) позволяют говорить о хороших перспективах в данной области волоконной оптики.

Работа была выполнена при поддержке гранта РНФ N 18 - 19 - 00733

\section{Литература}

[1] Philip St. J. Russell, Journal of Lightwave Technology 24, 4729 - 4749 (2006)

[2] N. A. Baranova and B. Ya. Zeldovich, Sov. Phys. JETP 53, 925 -929 (1981)

[3] A. Pryamikov, G. Alagashev, G. Falkovich and S. Turitsyn, Scientific Reports 10:2507 (2020) 